\title{
State-Dependent TMS Reveals Representation of Affective Body Movements in the Anterior Intraparietal Cortex
}

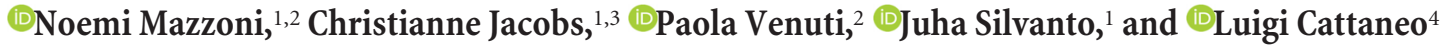 \\ ${ }^{1}$ Department of Psychology, Faculty of Science and Technology, University of Westminster, W1W 6UW London, United Kingdom, ${ }^{2}$ Department of \\ Psychology and Cognitive Science, University of Trento, 38068 Rovereto (TN), Italy, ${ }^{3}$ Faculty of Psychology and Educational Sciences, Université Catholique \\ de Louvain, Louvain-la-Neuve, 1348 Belgium, and ${ }^{4}$ Department of Neuroscience, Biomedicine and Movement, Section of Physiology and Psychology, \\ University of Verona, 37134 Verona, Italy
}

In humans, recognition of others' actions involves a cortical network that comprises, among other cortical regions, the posterior superior temporal sulcus (pSTS), where biological motion is coded and the anterior intraparietal sulcus (aIPS), where movement information is elaborated in terms of meaningful goal-directed actions. This action observation system (AOS) is thought to encode neutral voluntary actions, and possibly some aspects of affective motor repertoire, but the role of the AOS' areas in processing affective kinematic information has never been examined. Here we investigated whether the AOS plays a role in representing dynamic emotional bodily expressions. In the first experiment, we assessed behavioral adaptation effects of observed affective movements. Participants watched series of happy or fearful whole-body point-light displays (PLDs) as adapters and were then asked to perform an explicit categorization of the emotion expressed in test PLDs. Participants were slower when categorizing any of the two emotions as long as it was congruent with the emotion in the adapter sequence. We interpreted this effect as adaptation to the emotional content of PLDs. In the second experiment, we combined this paradigm with TMS applied over either the right aIPS, pSTS, and the right half of the occipital pole (corresponding to Brodmann's area 17 and serving as control) to examine the neural locus of the adaptation effect. TMS over the aIPS (but not over the other sites) reversed the behavioral cost of adaptation, specifically for fearful contents. This demonstrates that aIPS contains an explicit representation of affective body movements.

Key words: adaptation; anterior intraparietal sulcus; biological motion; emotional bodily expressions; emotions; TMS

\section{Significance Statement}

In humans, a network of areas, the action observation system, encodes voluntary actions. However, the role of these brain regions in processing affective kinematic information has not been investigated. Here we demonstrate that the aIPS contains a representation of affective body movements. First, in a behavioral experiment, we found an adaptation after-effect for emotional PLDs, indicating the existence of a neural representation selective for affective information in biological motion. To examine the neural locus of this effect, we then combined the adaptation paradigm with TMS. Stimulation of the aIPS (but not over pSTS and control site) reversed the behavioral cost of adaptation, specifically for fearful contents, demonstrating that aIPS contains a representation of affective body movements.

\section{Introduction}

Perception of movements of other living beings is crucial for survival in most species, to the extent that many vertebrate spe-

Received April 4, 2017; revised May 22, 2017; accepted June 11, 2017.

Author contributions: N.M., C.J., P.V., J.S., and L.C. designed research; N.M., C.J., and J.S. performed research; N.M. and L.C. analyzed data; N.M., C.J., P.V., J.S., and L.C. wrote the paper.

This work was supported by the ERC (336152) to J.S. and the F.R.S.-F.N.R.S. ("Charge de recherches") to C.J. We thank Antony P. Atkinson (Durham University), Paola Ricciardelli, and Rossana Actis-Grosso (University of MilanoBicocca) for sharing with us the stimuli; Birkbeck-University College of London Centre for Neurolmaging (BUCNI); and Christina Moutsiana, Benjamin de Haas, and Iroise Dumontheil for technical assistance during MRI scan acquisition.

The authors declare no competing financial interests. cies have specialized neural systems for action observation. In humans, a widespread network of interconnected brain areas [known as the action observation system (AOS)] underlies the comprehension of conspecifics' body movements and actions. This network includes the posterior superior temporal sulcus (pSTS; Puce and Perrett, 2003), and two mirror system areas, the putative human anterior intraparietal area (aIPS) and the ventral premotor/caudal inferior frontal gyrus complex (PMv/cIFG;

Correspondence should be addressed to Dr. Noemi Mazzoni, ODFLab, Department of Psychology and Cognitive Science, University of Trento, Via Matteo del Ben 5b, 38068, Rovereto (TN) Italy. E-mail: noemi.mazzoni@unitn.it. DOI:10.1523/JNEUROSCI.0913-17.2017

Copyright $\odot 2017$ the authors $\quad 0270-6474 / 17 / 377231-09 \$ 15.00 / 0$ 
Cattaneo and Rizzolatti, 2009). Several TMS studies have demonstrated that stimulating the pSTS, aIPS, and PMv/cIFG regions produces selective impairment in visual recognition of neutral actions (Grossman et al., 2005; Pobric and Hamilton, 2006; Candidi et al., 2008; Cattaneo et al., 2010; van Kemenade et al., 2012). But is the AOS also important for the encoding of the emotional aspects of biological motion?

The perception of affective stimuli, regardless of stimulus type, generally enhances the neural response of core affective systems, situated within the limbic system (Adolphs, 2002; Phillips et al., 2003) but emotional body movements are complex and their perception activates also a more widespread network of subcortical and cortical regions, related to analysis of visual body features and more generally to action observation and preparation (de Gelder, 2006, de Gelder et al., 2010, 2015; Tamietto and de Gelder, 2011). It is thus crucial to understand whether the activation within the AOS is a mere side-effect of the type of stimuli (body actions), independent from their content, or whether AOS activity is causally linked to emotional recognition. This issue has been explored in the literature in only two TMS studies; these found that perturbation of pSTS (Candidi et al., 2011) and inferior parietal lobule (Engelen et al., 2015) selectively improved the recognition of fearful body images. However, a limitation of both of these studies was that participants observed static images; human bodies are dynamic in nature and the brain substrates used in processing static postures are likely to differ from those engaged in perception of body movements. Furthermore, although conventional TMS paradigms can reveal the causal role of cortical regions in cognitive functions, they do not inform us about the neural representations in those regions.

Here we examined whether specific regions of the action observation network contain representations of affective body movements. This was accomplished by the use of state-dependent TMS, which enables the selectivity of neural representations in a cortical region to be assessed (Silvanto et al., 2008; Romei et al., 2016). This approach has been previously used to examine the selectivity of neural representations in various cognitive functions such as color and motion perception (Silvanto et al., 2007a; Cattaneo and Silvanto, 2008), numerical cognition (Kadosh et al., 2010), and action observation (Cattaneo et al., 2011, 2010; Sato et al., 2011; Jacquet and Avenanti, 2015). To examine the role of AOS in encoding the emotional aspects of dynamic biological motion, we used point-light displays (PLDs), also referred to as biological motion (BM) stimuli (Johansson, 1973), which allow isolation of motion signals from others visual cues. Kinematic information contained in PLDs is sufficient for detection of emotional content of human movements (Dittrich et al., 1996; Atkinson et al., 2004, 2007, 2012; Clarke et al., 2005; Chouchourelou et al., 2006; Alaerts et al., 2011). In Experiment 1, we examined behavioral adaptation effects of observed affective PLDs. We found an adaptation-like bias with incongruent stimuli recognized faster than congruent ones. In Experiment 2, we used the TMS-adaptation paradigm to examine the cortical locus of adaptation effects observed in Experiment 1. TMS over the aIPS, but not over pSTS nor over a visual control area, reversed the behavioral adaptation for fearful stimuli, indicating that this region contains neural representations selective for the fearful characteristics of human movements.

\section{Materials and Methods}

Visual stimuli and validation of emotional valence. A total of 20 PLDs were presented, depicting 10 different expressions of happiness and fear, respectively. These stimuli are part of a wider dataset created by Atkinson et
Table 1. Results of comparisons between the three emotional valences of PLDs for accuracy, intensity, and movement assessed in the pilot study

\begin{tabular}{|c|c|c|c|c|c|c|}
\hline & \multicolumn{2}{|c|}{ Accuracy } & \multicolumn{2}{|c|}{ Movement } & \multicolumn{2}{|c|}{ Intensity } \\
\hline & V & $p$ & V & $p$ & V & $p$ \\
\hline Fearful vs happy & 30 & 0.39 & 12.5 & 0.139 & 26 & 0.919 \\
\hline Fearful vs neutral & 21 & 0.034 & 31 & 0.759 & 55 & 0.002 \\
\hline Happy vs neutral & 28.5 & 0.154 & 45 & 0.083 & 55 & 0.002 \\
\hline
\end{tabular}

$V$ is the value of the test statistic (Wilcoxon Signed-Rank Test for paired samples).

al. (2004, 2012). The PLDs consisted of 2-s-long digitalized video clips (for details, see Atkinson et al., 2012), displaying a single actor represented as 13 white dot-lights moving on a black background. The dots were positioned over the head and the main joints (1 dot over each ankle, knee, hip, elbow, shoulder, and hand) of the actor. Examples of the stimuli can be viewed at http://community.dur.ac.uk/a.p.atkinson/Stimuli.html. We selected happy and fearful stimuli because they are approximately equally arousing emotions, with opposite emotional valences (positive or negative). Before the main experiments, we ran a pilot study to validate the PLDs in terms of quantity of movement contained in the PLDs and of type and intensity of portrayed emotion. Sixteen healthy adults took part in this pilot experiment ( 13 females, mean age $=29.63, \mathrm{SD}=7.65)$. All the participants provided informed consent before participating in the experiment. They were seated in front of a 24 in monitor at a distance of $\sim 60 \mathrm{~cm}$. The stimuli were presented foveally. Each PLD was presented once, and for each video participants were asked to recognize the conveyed emotion among four options (fear, happiness, neutral, and other) by pressing the corresponding button on the keyboard. The response options (appearing on the screen after each stimulus) were indicated with a label placed over the keys " $\mathrm{F}-\mathrm{H}, \mathrm{J}$ " and were randomized across participants. After the emotion recognition task, participants were asked to rate the "intensity of the emotion" and the "quantity of movement" on a scale from 1 to 5 , using the numeric keys on the top of the keyboard. Stimuli were presented and responses recorded with E-Prime 2.0 (Psychology Software Tools). For each individual PLD, we calculated the accuracy of emotion categorization, the rated intensity of the emotion, and the rated quantity of movement. Data distribution was tested for normality with Shapiro-Wilk's test. Accuracy, intensity, and movement were not normally distributed, so they were analyzed using a nonparametric test for paired data, the Wilcoxon signed rank test with continuity correction. Significance thresholds were Bonferroni-corrected for three multiple comparisons (for each variable, we compared results between the 3 emotional valences; hence, the critical $\alpha$ was set as $p<0.017)$. There were no significant differences between the happy and fearful movements for accuracy, movement, and intensity, whereas, predictably, the neutral movements were rated as less intense compared with the two emotions (Table 1). This implies that the stimuli used in Experiments 1 and 2 (i.e., fearful and happy PLDs) do not differ in terms of 1) recognizability between the emotional categories, 2) intensity of the expressed emotion, or 3) quantity of movement contained in the stimuli.

\section{Experiment 1: behavioral assessment of adaptation to observed emotional body movements}

Participants. Twenty-six healthy adults (14 females, 12 males; mean age $=23.58$ years, $\mathrm{SD}=2.95$ years) took part in the behavioral study (Experiment 1). All participants had normal or corrected-to-normal vision. Before the experiment, all participants provided written informed consent in accordance with the Declaration of Helsinki.

Design and procedure. Participants were seated in a comfortable chair in front of a 24 in computer screen at a distance of $\sim 60 \mathrm{~cm}$. E-Prime version 2.0 (Psychology Software Tools) software was used for stimulus presentation and response recordings. The study consisted of 12 adaptation blocks (6 with happy and 6 with fearful adapters), consisting of a $1 \mathrm{~min}$ adapting period followed by eight test trials. Each trial began with a white central fixation cross over a black background, lasting for $10 \mathrm{~s}$. This was followed by an adaptation period in which the same PLD was repeated 30 times (for a total duration of $60 \mathrm{~s}$ ). Participants were asked to simply watch the stimuli and focus on the emotion expressed by the actor. The order of adaptation blocks was randomized. At the end of 
adaptation, a screen appeared asking participant to "Get ready for the task", after which eight test stimuli (4 fearful and 4 happy PLDs) were presented. Half of the test stimuli were emotionally congruent and half were emotionally incongruent with the adapter, and their order was randomized. The test stimuli and the adapter stimuli belong to the same dataset, i.e., the same stimulus could be used as an adapter in one block or as a test stimulus in another block. However, in single blocks, the adapter stimulus was always different from the test stimuli presented thereafter. In other words, every stimulus could appear randomly as adapter or as a test in different blocks, but not in the same block. The movie clip was presented centrally. Simultaneously with the stimulus presentation, the question "Which emotion?" appeared on the upper part of the screen, and the two response options ("Fear" and "Happiness") were presented on the lower part of the monitor. For each test stimulus, participants were asked to categorize the expressed emotion as fast as possible by key-press. The response options were indicated with a label placed over the keys " $G$ " and " $\mathrm{H}$ ", and the key-emotion correspondence was randomized across participants. Participants were asked to respond using the index and the middle finger of their right hand. The PLD was presented for a maximum of $2 \mathrm{~s}$, whereas the question and the response period lasted until participants responded. Accuracy and response times (RTs) were recorded.

Data analyses. The dependent variable was mean RTs. Only correct responses were included in the analyses (the overall error rate was $4.43 \%$ ). Data distributions failed the normality (Shapiro-Wilk's test) and homoscedasticity of variance (Bartlett's test) tests. To normalize the distribution, the averaged RTs were log-transformed before analyses $(\operatorname{logRT})$. A two-way repeated-measures ANOVA was conducted with emotional content of the test stimuli ("emoTest": fear or happiness) and emotional congruence between test and adapter stimuli (congruent or incongruent) as within-subject factors. Post hoc comparisons were performed with two-tailed paired-samples $t$ tests with correction of the significance threshold for multiple comparisons whenever appropriate. All analyses were performed using R v3.3.1 (R Development Core Team, 2016).

\section{Experiment 2: effects of TMS on perceptual adaptation}

Participants. Seventeen healthy adults (11 females, 6 males; mean age $=$ $25.63, \mathrm{SD}=5.17)$ participated in the TMS experiment (Experiment 2 ). Three participants were excluded from the analysis because of difficulties in determining their resting motor threshold. In these participants, the TMS stimulation over M1 did not produce any visible hand twitch, and no motor sensation was perceived. Hence, the final analyses were performed on a total of 14 participants. Participants in the TMS experiment were screened for MRI and TMS contraindication before the experiment

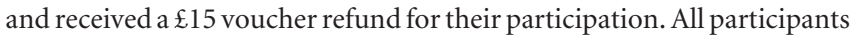
had normal or corrected-to-normal vision. Before the experiment, all participants provided written informed consent. The protocol was approved by the University of Westminster's ethical committee in accordance with the Declaration of Helsinki.

Neuronavigation and identification of stimulation sites on individual anatomy. We used MRI-guided neuronavigation (BrainInnovation BV) for accurate positioning of the TMS coil. For each participant, a high resolution T1-weighted MPRAGE scan (176 partitions, $1 \times 1 \times 1 \mathrm{~mm}$, flip angle $=7^{\circ}, \mathrm{TI}=1000 \mathrm{~ms}$, $\mathrm{TE}=3.57 \mathrm{~ms}, \mathrm{TR}=8.4 \mathrm{~ms}$ ) was acquired before the TMS experiment. Structural MRI images were obtained with a $1.5 \mathrm{~T}$ whole-body TIM Avanto System (Siemens Healthcare), at the Birkbeck/University College London Centre for NeuroImaging, with a 32channel head coil. A 3D reconstruction of the gray matter surfaces and the scalp was created for each participant, which were coregistered to the participant's head to position the coil over the site of stimulation and to control coil position throughout the experiment. In each participant, three different sites in the right hemisphere were stimulated: the right pSTS, the right aIPS, and a posterior occipital control area located next to the midline. The three loci were identified on the basis of macroanatomical landmarks. Specifically, the pSTS was targeted over the transition between its posterior segment and its horizontal segment (for an overview of STS anatomy, see Ochiai et al., 2004). We defined the aIPS as the most rostral part of the IPS at the intersection between the postcentral gyrus and the IPS (Caspers et al., 2006). Control TMS was applied to a site corresponding to a secondary visual area not primarily implied in coding for emotional aspect of visual stimuli, located between BA 17 and BA 18 (Fig. 1).

TMS. Biphasic TMS pulses were applied with a figure-of-eight coil (D70 mm coil) connected to a Magstim Rapid2 stimulator. At first we searched in each participant the visually assessed resting motor threshold (rMT), defined as the stimulator's output intensity necessary to obtain a visible twitch in the contralateral intrinsic hand muscles in exactly $50 \%$ of trials in a series of at least eight consecutive pulses (Rossini et al., 1994). The intensity of stimulation in the actual experiment was set to $120 \%$ of the individual's rMT with a maximum of $65 \%$ maximal stimulator output due to coil overheating and limiting discomfort to participants. The coil was attached to a Magstim coil stand and placed tangentially to the scalp. Coil orientation was medial-lateral with the handle pointing laterally and slightly posteriorly $\left(70^{\circ}\right.$ from the midline) for the aIPS position, to induce a current in the underlying cortical tissue approximately perpendicular to the IPS. A similar orientation was used for the stimulation of pSTS, but with the coil handles pointing upward. Due to pSTS proximity to the ears, in some participants the coil orientation was changed to minimize discomfort. For the occipital (control) stimulation, the coil was positioned perpendicular to the midline with the handle pointing outward. TMS was delivered in triplets. In every trial participants received three $10 \mathrm{~Hz}$ pulses time-locked to the onset of the PLD, starting synchronously with the visual stimulus.

Procedure. The TMS paradigm was identical to that used in Experiment 1 described above. Every block consisted of 1 min of adapting period followed by eight test trials. A total of 12 adapter stimuli ( 6 happy and 6 fearful PLDs) and 96 test stimuli were presented for each of the three sites of stimulation. The order of adaptation blocks was randomized. During the adaptation period the same PLD was repeated 30 times (for $60 \mathrm{~s}$ ). Participants were asked to simply watch the adapter stimuli and focus on the emotion expressed by the actor. At the end of adaptation, eight test stimuli ( 4 fearful and 4 happy PLDs) were presented. Half of the test stimuli were emotionally congruent (i.e., same emotion) and half were emotionally incongruent (i.e., different emotion) with the adapter, and their order was randomized. Participants were asked to categorize the expressed emotion (fear or happiness) as fast as possible by key-press, using the index and the middle finger of their right hand (Fig. 2). Accuracy and RTs were recorded. The three stimulation sites (right pSTS, right aIPS, and the control site) were stimulated on the same day with 30 min of delay between sessions. The order of stimulation sites was counterbalanced between participants. Participants wore earplugs and were seated in a comfortable chair in a quiet room, in front of a 24 in computer screen at a distance of $60 \mathrm{~cm}$, with their head on a chinrest.

Data analyses. All analyses were performed using R v3.3.1 (R Development Core Team, 2016). The dependent variable was the mean of RTs. Only correct responses were included in the analyses. Data were tested for normality (Shapiro test) and homoscedasticity of variance (Bartlett test). To normalize the distribution, the averaged RTs were log-transformed before analyses $(\log \mathrm{RT})$. A three-way repeated-measures ANOVA $(3 \times$ $2 \times 2$ ) was performed. The site of TMS stimulation ("stimSite"), the emotional valence of the test stimuli (emoTest) and the emotional congruence between test and adapter stimuli ("congruence") were entered as within-subject factors. Post hoc comparisons were performed with twotailed paired-samples $t$ tests. The significance threshold for the $p$ values was corrected for multiple comparisons when appropriate. As a measure of the effects size, the generalized eta-squared $\left(\eta^{2}\right)$ is reported when appropriate. In addition, we calculated the Cohen's d for the significant comparisons using bootstrap resamples method (Gerlanc and Kirby, 2015). The number of bootstrap resamples $(R)$ was set at 2000. Bootstrap Cohen's d effect size measures and their corresponding 95\% confidence intervals (CIs) are also reported when appropriate.

\section{Results}

Experiment 1: behavioral evidence of perceptual adaptation to the emotional content of PLDs

In Experiment 1, the overall error rate was $4.43 \%$. A summary of the results of Experiment 1 is presented in Table 2 and Figure 3. 


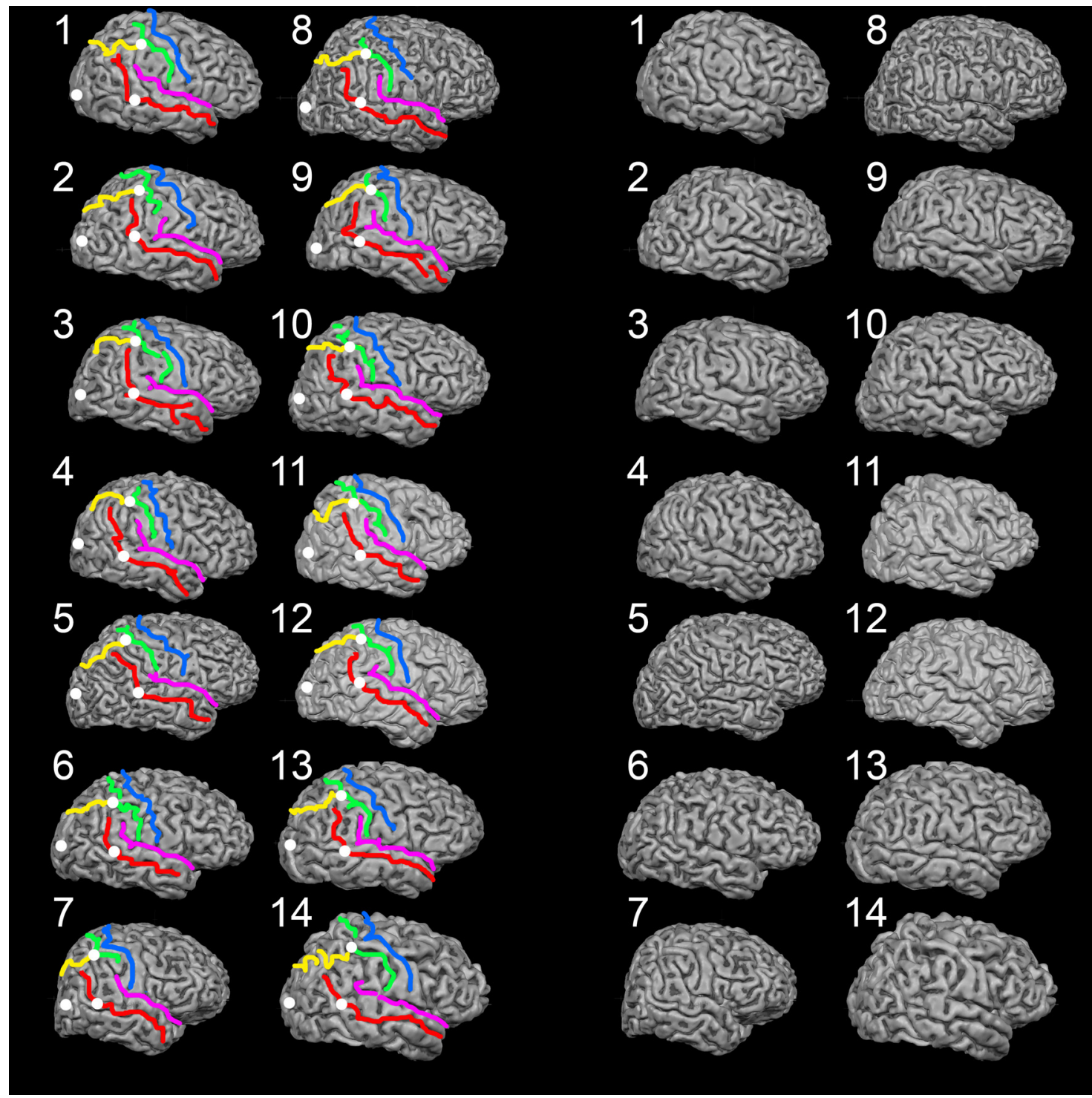

Figure 1. Representation of stimulation sites and respective anatomical landmarks. Right, Individual renderings of the gray-white matter border in each of the 14 participants. Left, The same brains as in the right are shown with the main anatomical landmarks used for localization of TMS targets. Blue, Central sulcus; green, postcentral sulcus; yellow, intraparietal sulcus; purple, Silvian fissure; red, superior temporal sulcus. The three stimulation sites (aIPS, pSTS, and control) are represented with white spots.

The two-way ANOVA showed a significant main effect of congruence $\left(F_{(1,25)}=7.31, p=0.012\right)$ with incongruent stimuli being recognized faster than congruent ones, while the interaction between emoTest and congruence was not significant $\left(F_{(1,25)}=0.856\right.$, $p=0.364 ; \eta^{2}=0.014 ;$ Cohen's $\left.\mathrm{d}=-0.236 ; \mathrm{CI}=-0.660,0.166\right)$.

Experiment 2: state-dependent effects of TMS over aIPS on explicit categorization of fearful PLDs

In Experiment 2, the overall error rate was 3.87\%. The three-way ANOVA showed a significant main effect of congruence $\left(F_{(1,13)}=\right.$ 14.994, $p=0.002)$, with congruent stimuli being recognized slower than incongruent ones (mean RTs: congruent $=1194 \mathrm{~ms}$; incongruent $=1148 \mathrm{~ms}$ ), suggesting the presence of an adaptation after-effect for affective PLDs and confirming the results of the behavioral experiment (Experiment 1). More importantly, we found a significant three-way interaction between stimSite, emoTest, and congruence $\left(F_{(2,26)}=3.546, p=0.043\right)$. To better understand this interaction, we performed three $2 \times 2$ repeatedmeasures ANOVAs in the three stimulation sites separately, with emoTest and congruence as within factors. We found a significant main effect of congruence in the control site $\left(F_{(1,13)}=9.329\right.$; $\left.p=0.009 ; \eta^{2}=0.017\right)$ and in $\operatorname{pSTS}\left(F_{(1,13)}=9.393 ; p=0.009\right.$; $\left.\eta^{2}=0.029\right)$, showing that the adaptation after-effect persisted and hence suggesting that TMS stimulation did not have any effect on those two brain areas. On the contrary, ANOVA in aIPS showed a significant interaction between emoTest and congruence $\left(F_{(1,13)}=8.474 ; p=0.012 ; \eta^{2}=0.022\right)$, but no significant main effects. In particular, the adaptation after-effect was still present for happy test stimuli ( $p=0.009$; Cohen's $\mathrm{d}=-0.311$; $\mathrm{CI}=-1.114$, 0.459 ) with incongruent stimuli recognized faster than congruent ones. Conversely, the adaptation after-effect was completely abolished for fearful test stimuli, to the point that we observed a trend toward an inversion of the adaptation effects, i.e., congruent test stimuli were recognized faster than congruent ones $(p=0.066$; Cohen's d $=0.267 ; \mathrm{CI}=-0.459,1.075)$. 


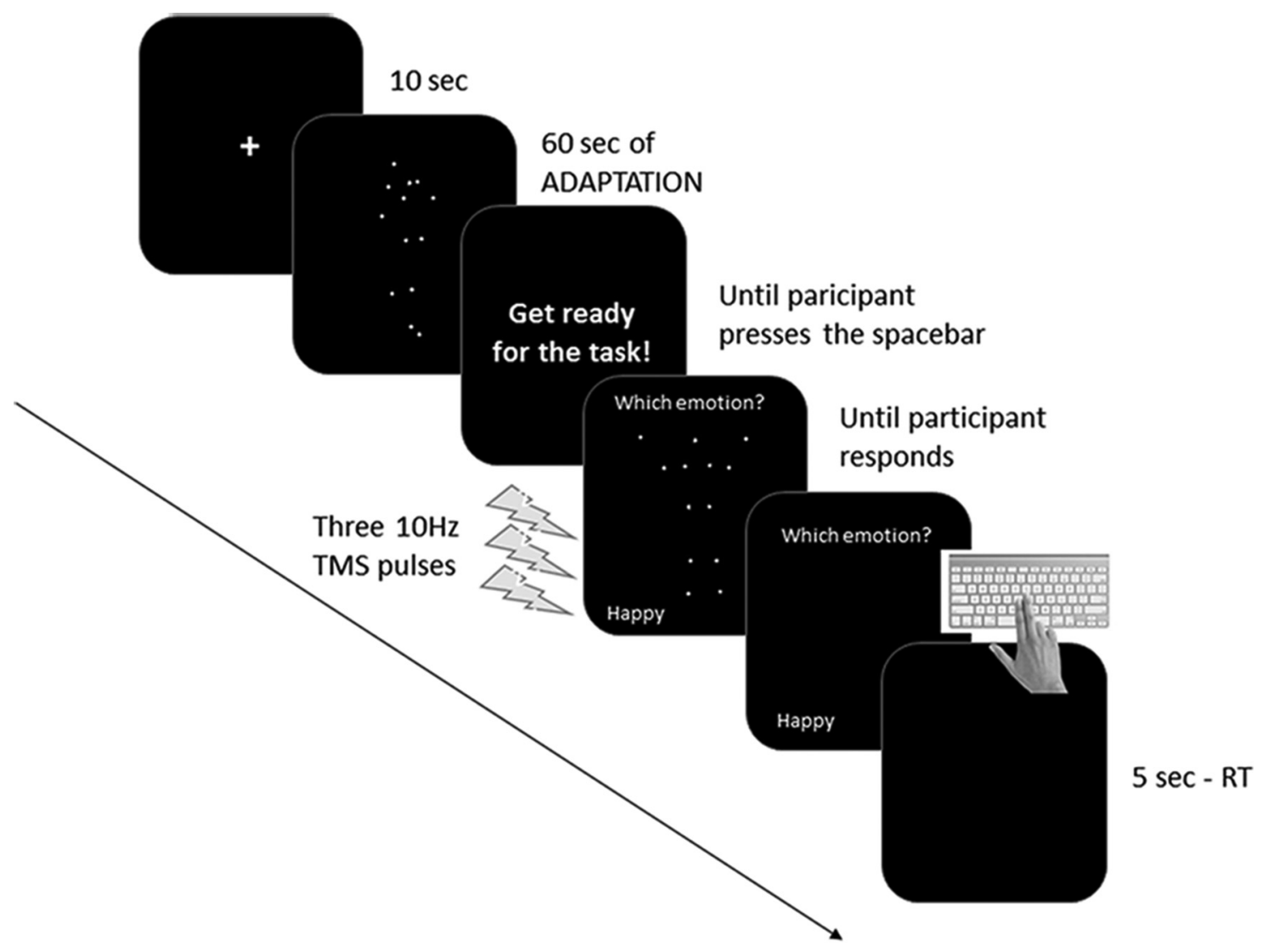

Figure 2. Timeline of TMS experiments. Every block consisted of 1 min of adapting period followed by eight test trials. During the adaptation period the same PLD was presented 30 times and participants were asked to simply watch the adapter stimuli. At the end of adaptation, 4 fearful and 4 happy test stimuli were presented. Participants were asked to categorize the expressed emotion by key press. Three $10 \mathrm{~Hz}$ TMS pulses were applied at the onset of every test stimulus.

Table 2. Mean and SE of RTs in all the conditions in Experiment 1

\begin{tabular}{llll}
\hline emoTest & Congruence & Mean RT, ms & SE, ms \\
\hline Fear & Congruent & 1317 & 50.32 \\
Fear & Incongruent & 1219 & 46.75 \\
Happiness & Congruent & 1267 & 43.92 \\
Happiness & Incongruent & 1252 & 36.84 \\
\hline
\end{tabular}

\section{Discussion}

\section{Perceptual adaptation to emotional content of PLDs}

In the first experiment, we investigated the perceptual aftereffects produced by repeated observation of emotional PLDs. When categorizing an affective PLD, participants' performance was markedly biased (slower RTs) by their previous exposure to congruent emotions. Adaptation aftereffects for PLDs have been reported previously for different features of biological motion, including gender characteristics (Troje et al., 2006), action category (van Boxtel and Lu, 2013; de la Rosa et al., 2014), and spatial orientation of observed bodily trajectories (Jackson and Blake, 2010; Theusner et al., 2011). Also judgments on-hand-object interactions in PLDs are susceptible to visual adaptation: viewing the grasping of a light object biases the judgment on subsequent grasped objects that appear heavier (Barraclough et al., 2009). In addition to, a number of studies reported adaptation aftereffects to affective facial (Russell and Fehr, 1987; Webster et al., 2004; Fox and Barton, 2007; Webster and MacLeod, 2011) and vocal expressions (Skuk and Schweinberger, 2013; Bestelmeyer et al., 2014). It remained unexplored whether emotional bodily movements can produce adaptation aftereffects. Our study fills this gap, providing the first evidence that perception of emotional whole-body movements can undergo selective perceptual adaptation.

Absence of state-dependent effects of TMS on the early visual cortex (control condition)

The aim of Experiment 2 was to examine the neural locus of this adaptation effect for affective dynamic bodily expressions. Following control stimulation we found adaptation after-effects similar to those observed in Experiment 1, i.e., a disadvantage in recognizing PLDs emotionally congruent with the adapter sequences (Fig. 4). Given the assumptions of TMS-adaptation paradigms, we did not expect any effect of TMS on this region, because the adapted features (bodily movements) are not supposed to be coded in the early visual cortex. Indeed, the earliest visual representation of bodies along the visual pathways is in the lateral occipital complex, way more rostral than the area that we chose as control (Downing et al., 2001). Studies in blindsight patients suggest that the processing of emotional information can efficaciously occur despite lesions of the early visual areas, either when conveyed by faces (de Gelder et al., 1999; Morris et al., 2001) or by body postures (de Gelder and Hadjikhani, 2006). Accordingly, in another study, TMS perturbation of V1 impaired the discrimination of neutral, but not emotional, body postures, supporting the hypothesis that the encoding of the emotional content does not depend on V1 (Filmer and Monsell, 2013).

\section{Absence of state-dependent effects of TMS on the pSTS}

In contrast to the early visual cortex, the pSTS is tuned to biological motion. However, to our surprise, no state-dependent effects 


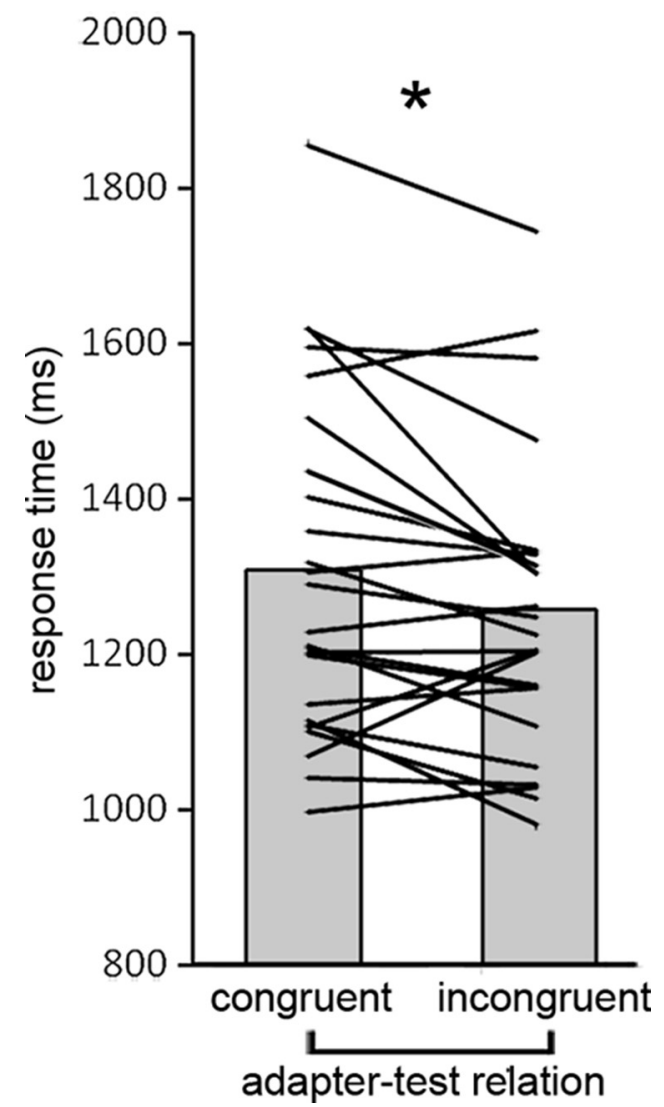

Figure 3. Visualization of results from Experiment 1. The performance of each participant is represented with a black bar. The gray columns represent the mean of RTs in congruent and incongruent conditions. Main analysis revealed an adaptation after-effect for affective PLDs with congruent stimuli being recognized significantly slower than incongruent ones. ${ }^{*}$ indicates significant difference between congruent and incongruent condition.

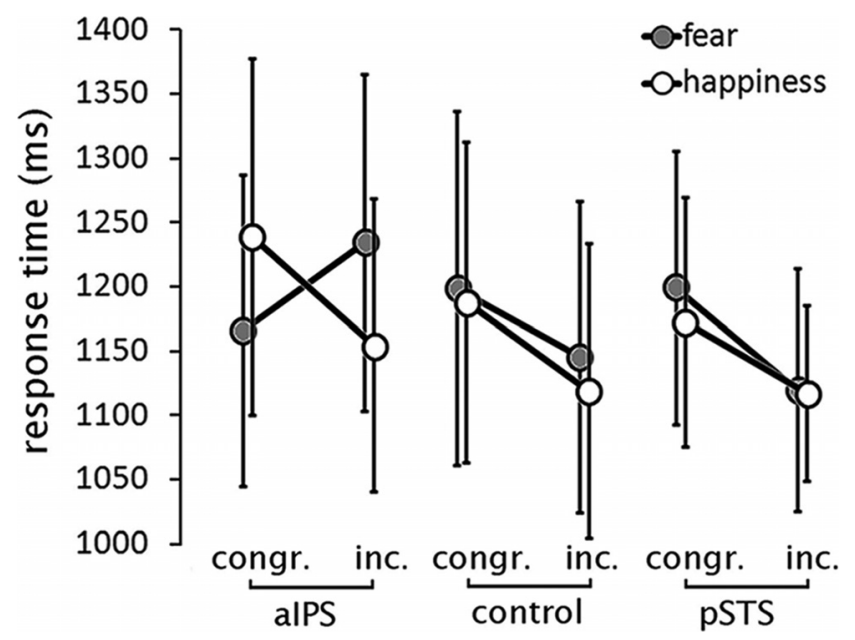

Figure 4. Visualization of results from Experiment 2. Mean RTs are shown, classified according to emotion in the test PLD (happiness or fear); congruence with the adapter sequence (congruent or incongruent, indicated in the figure as "congr." or "inc." respectively); and to the site of TMS (aIPS, pSTS, or occipital control). The vertical bars represent the SE.

of TMS were found. We interpreted this finding in the light of the functional specialization of the pSTS. The integrity of STS is fundamental to biological motion identification (Vaina et al., 1990; Grossman et al., 2005; Saygin, 2007), it encodes low-level pictorial aspects of BM (Cattaneo et al., 2010), and it represents bodily movements separately for different body parts (upper limb, face, whole-body, gaze; Hein and Knight, 2008), probably in a viewpoint-invariant manner (Grossman et al., 2010). In one TMS study, stimulation of pSTS improved the visual match of body forms specifically for fearful body postures (Candidi et al., 2011). However this type of task relies on pictorial analysis likely encoded in PSTS, whereas we asked to recognize the emotional meaning of dynamic PLDs, potentially related to higher level of action representation implemented in aIPS (Fogassi et al., 2005; Hamilton and Grafton, 2006; Shmuelof and Zohary, 2006; Cattaneo et al., 2010). Similarly, another study (Tseng et al., 2014) showed that the specific effects of static fearful facial displays as distracters in a visual search task could be disrupted by anodal transcranial direct current stimulation over the right pSTS.

\section{State-dependent effects of TMS on the aIPS}

TMS stimulation over aIPS reduced significantly the cost of adaptation, and even produced a reversal of the cost of this effect, turning it into behavioral advantage. This finding is diagnostic for the presence of neurons that were affected by adaptation changes in the stimulated area (Silvanto et al., 2008; Romei et al., 2016; Silvanto and Pascual-Leone, 2008). TMS-adaptation is based on the phenomenon that the impact of TMS depends on the ongoing activity in the targeted region. TMS, which in the absence of adaptation impairs behavior, can induce a facilitatory effect if neurons in the targeted area have undergone adaptation (Silvanto et al., $2007 \mathrm{a}, \mathrm{b})$. The outcome of this differential effect of TMS on adapted versus nonadapted neuronal representations is the removal/reversal of the behavioral adaptation effect (Silvanto et al., 2007b; Silvanto and Muggleton, 2008; Romei et al., 2016). In the present study, the removal of behavioral adaptation to fearful stimuli by aIPS TMS indicates that this region contains neuronal representations tuned to affective movements.

Interestingly, the effects of TMS over aIPS were limited to fearful PLDs, and were absent for happy PLDs. What do we know about action representation in the aIPS? Several lines of evidence in both human (Arfeller et al., 2013) and nonhuman primates (Borra et al., 2008; Nelissen et al., 2011; Rizzolatti et al., 2014) indicate that action representations are hierarchically organized between a low-level pictorial representation in pSTS, and a more abstract representation of action goals in the parietofrontal system including the aIPS (Tunik et al., 2007; Cattaneo et al., 2010). The aIPS generalizes actions across effectors (Cattaneo et al., 2010) and is capable of encoding action invariants such as action endpoints, outcomes, and environmental changes produced by actions (Hamilton and Grafton, 2006, 2008). In Experiment 2, we found evidence that the explicit recognition of the emotional component of body movements relies in part on the parietal node of the AOS. Visual observation of emotional body movements produces activity in several brain networks, such as visual regions, the limbic network, and the AOS (de Gelder et al., 2004, 2010; Tamietto et al., 2007; Pichon et al., 2008; van de Riet et al., 2009; Meeren et al., 2013). There are several different neural mechanisms by which the human brain can identify and categorize observed affective displays. The capacity to recognize nonverbal affective communications generally relies on a core system that is likely to be located within the limbic system (LeDoux, 1996; Öhman and Mineka, 2001; Adolphs et al., 2003). However, our findings indicate that (limitedly to explicit processes) some subtypes of emotional body movements may be encoded as purposeful, goal-directed actions in the aIPS. Conversely, the pSTS, 
being the site of simple movement representation, does not seem to contain a specific representation of affective movements.

\section{Dissociation between fear and happiness in the aIPS}

State-dependent effects of TMS in aIPS were specific to fearful PLDs (Fig. 4). Why do fearful stimuli seem to be predominantly represented in the aIPS compared with happy stimuli? A possible explanation is that the affective state of fear itself is represented in the aIPS. Alternatively, it is possible the motor patterns expressing fear have characteristics that are best encoded by the aIPS, which preferentially processes goal-directed, purposeful movements (Cattaneo et al., 2010). The fearful bodily movements represented in our stimuli were in most cases directed toward a position in space as they depicted self-protective or avoidance body movements directed away from specific threatening agents (see example videos at http:// community.dur.ac.uk/a.p.atkinson/Stimuli.html). On the contrary, happy stimuli (e.g., exulting, clapping hands, joyful hopping) were not directed toward or away from specific sectors in space. Therefore, the fear-happiness dissociation could be explained by a higher goal-directedness or space orientation in fearful movements compared with happy ones. From an evolutionary point of view, the emotional movements are communicative in nature, and our brain's prompt reactions to them is essential for the survival (Darwin, 1872; Ekman, 1957; Grèzes et al., 2007). In this sense, each emotional subtype has an own identity, and its affective state is not dissociable from its stereotyped communicative motor behavior. The effective communication of fearful content is more likely relied on goal-directed and spatially oriented actions than happiness. We therefore favor the hypothesis that fearful movements have a more "praxic" and "goal-directed" quality compared with happiness. In line with that, several studies have reported that the motor system is specifically tuned to fearful body movements as shown by changes in corticospinal excitability in response to fearful body postures (Borgomaneri et al., 2012, 2015), fearful facial expressions (Schutter et al., 2008), and negative natural complex scenes (Borgomaneri et al., 2014). However, the role of activity in the corticospinal system in action comprehension remains unclear.

\section{Conclusions}

We conclude that, while performing explicit categorizations (i.e., high-level cognitive task), the human brain considers fearful emotional body movements as goal-directed actions. This conclusion is supported by the specific recruitment of the cortical network that is specialized in processing actions. The AOS therefore contains representations of affective movements, as long as these are interpreted as finalistic, goal-directed, meaningful actions. On the contrary, the pSTS is known to encode BM according to its characteristic kinematic, distinguishing it from nonhuman motion, and is apparently not encoding specifically neither fearful nor happy bodily actions.

\section{References}

Adolphs R (2002) Neural systems for recognizing emotion. Curr Opin Neurobiol 12:169-177. CrossRef Medline

Adolphs R, Tranel D, Damasio AR (2003) Dissociable neural systems for recognizing emotions. Brain Cogn 52:61-69. CrossRef Medline

Alaerts K, Nackaerts E, Meyns P, Swinnen SP, Wenderoth N (2011) Action and emotion recognition from point light displays: an investigation of gender differences. PLoS One 6:e20989. CrossRef Medline

Arfeller C, Schwarzbach J, Ubaldi S, Ferrari P, Barchiesi G, Cattaneo L (2013) Whole-brain haemodynamic after-effects of $1-\mathrm{Hz}$ magnetic stimulation of the posterior superior temporal cortex during action observation. Brain Topogr 26:278-291. CrossRef Medline

Atkinson AP, Dittrich WH, Gemmell AJ, Young AW (2004) Emotion perception from dynamic and static body expressions in point-light and full-light displays. Perception 33:717-746. CrossRef Medline

Atkinson AP, Tunstall ML, Dittrich WH (2007) Evidence for distinct contributions of form and motion information to the recognition of emotions from body gestures. Cognition 104:59-72. CrossRef Medline

Atkinson AP, Vuong QC, Smithson HE (2012) Modulation of the face- and body-selective visual regions by the motion and emotion of point-light face and body stimuli. Neuroimage 59:1700-1712. CrossRef Medline

Barraclough NE, Keith RH, Xiao D, Oram MW, Perrett DI (2009) Visual adaptation to goal-directed hand actions. J Cogn Neurosci 21:1806-1820. CrossRef Medline

Bestelmeyer PE, Maurage P, Rouger J, Latinus M, Belin P (2014) Adaptation to vocal expressions reveals multistep perception of auditory emotion. J Neurosci 34:8098-8105. CrossRef Medline

Borgomaneri S, Gazzola V, Avenanti A (2012) Motor mapping of implied actions during perception of emotional body language. Brain Stimul 5:70-76. CrossRef Medline

Borgomaneri S, Gazzola V, Avenanti A (2014) Temporal dynamics of motor cortex excitability during perception of natural emotional scenes. Soc Cogn Affect Neurosci 9:1451-1457. CrossRef Medline

Borgomaneri S, Vitale F, Gazzola V, Avenanti A (2015) Seeing fearful body language rapidly freezes the observer's motor cortex. Cortex 65:232-245. CrossRef Medline

Borra E, Belmalih A, Calzavara R, Gerbella M, Murata A, Rozzi S, Luppino G (2008) Cortical connections of the macaque anterior intraparietal (AIP) area. Cereb Cortex 18:1094-1111. CrossRef Medline

Candidi M, Urgesi C, Ionta S, Aglioti SM (2008) Virtual lesion of ventral premotor cortex impairs visual perception of biomechanically possible but not impossible actions. Soc Neurosci 3:388-400. CrossRef Medline

Candidi M, Stienen BM, Aglioti SM, de Gelder B (2011) Event-related repetitive transcranial magnetic stimulation of posterior superior temporal sulcus improves the detection of threatening postural changes in human bodies. J Neurosci 31:17547-17554. CrossRef Medline

Caspers S, Geyer S, Schleicher A, Mohlberg H, Amunts K, Zilles K (2006) The human inferior parietal cortex: cytoarchitectonic parcellation and interindividual variability. Neuroimage 33:430-448. CrossRef Medline

Cattaneo L, Rizzolatti G (2009) The mirror neuron system. Arch Neurol 66:557-560. CrossRef Medline

Cattaneo L, Sandrini M, Schwarzbach J (2010) State-dependent TMS reveals a hierarchical representation of observed acts in the temporal, parietal, and premotor cortices. Cereb Cortex 20:2252-2258. CrossRef Medline

Cattaneo L, Barchiesi G, Tabarelli D, Arfeller C, Sato M, Glenberg AM (2011) One's motor performance predictably modulates the understanding of others' actions through adaptation of premotor visuo-motor neurons. Soc Cogn Affect Neurosci 6:301-310. CrossRef Medline

Cattaneo Z, Silvanto J (2008) Investigating visual motion perception using the transcranial magnetic stimulation-adaptation paradigm. Neuroreport 19:1423-1427. CrossRef Medline

Chouchourelou A, Matsuka T, Harber K, Shiffrar M (2006) The visual analysis of emotional actions. Soc Neurosci 1:63-74. CrossRef Medline

Clarke TJ, Bradshaw MF, Field DT, Hampson SE, Rose D (2005) The perception of emotion from body movement in point-light displays of interpersonal dialogue. Perception 34:1171-1180. CrossRef Medline

Darwin CR (1872) The expression of the emotions in man and animals. London: John Murray.

de Gelder B (2006) Towards the neurobiology of emotional body language. Nat Rev Neurosci 7:242-249. CrossRef Medline

de Gelder B, Hadjikhani N (2006) Non-conscious recognition of emotional body language. Neuroreport 17:583-586. CrossRef Medline

de Gelder B, Vroomen J, Pourtois G, Weiskrantz L (1999) Non-conscious recognition of affect in the absence of striate cortex. Neuroreport 10: 3759-3763. CrossRef Medline

de Gelder B, Snyder J, Greve D, Gerard G, Hadjikhani N (2004) Fear fosters flight: a mechanism for fear contagion when perceiving emotion expressed by a whole body. Proc Natl Acad Sci U S A 101:16701-16706. CrossRef Medline

de Gelder B, Van den Stock J, Meeren HK, Sinke CB, Kret ME, Tamietto M (2010) Standing up for the body: recent progress in uncovering the 
networks involved in the perception of bodies and bodily expressions. Neurosci Biobehav Rev 34:513-527. CrossRef Medline

de Gelder B, de Borst AW, Watson R (2015) The perception of emotion in body expressions. Wiley Interdiscip Rev Cogn Sci 6:149-158. CrossRef Medline

de la Rosa S, Streuber S, Giese M, Bülthoff HH, Curio C (2014) Putting actions in context: visual action adaptation aftereffects are modulated by social contexts. PLoS One 9:e86502. CrossRef Medline

Dittrich WH, Troscianko T, Lea SE, Morgan D (1996) Perception of emotion from dynamic point-light displays represented in dance. Perception 25:727-738. CrossRef Medline

Downing PE, Jiang Y, Shuman M, Kanwisher N (2001) A cortical area selective for visual processing of the human body. Science 293:2470-2473. CrossRef Medline

Ekman P (1957) A methodological discussion of nonverbal behavior. J Psychol 43:141-149. CrossRef

Engelen T, de Graaf TA, Sack AT, de Gelder B (2015) A causal role for inferior parietal lobule in emotion body perception. Cortex 73:195-202. CrossRef Medline

Filmer HL, Monsell S (2013) TMS to V1 spares discrimination of emotive relative to neutral body postures. Neuropsychologia 51:2485-2491. CrossRef Medline

Fogassi L, Ferrari PF, Gesierich B, Rozzi S, Chersi F, Rizzolatti G (2005) Parietal lobe: from action organization to intention understanding. Science 308:662-667. CrossRef Medline

Fox CJ, Barton JJ (2007) What is adapted in face adaptation? The neural representations of expression in the human visual system. Brain Res 1127: $80-89$. CrossRef Medline

Gerlanc D, Kirby K (2015) bootES: bootstrap effect sizes. R package version 1.2. https://CRAN.R-project.org/package=bootES

Grèzes J, Pichon S, de Gelder B (2007) Perceiving fear in dynamic body expressions. Neuroimage 35:959-967. CrossRef Medline

Grossman ED, Battelli L, Pascual-Leone A (2005) Repetitive TMS over posterior STS disrupts perception of biological motion. Vision Res 45:28472853. CrossRef Medline

Grossman ED, Jardine NL, Pyles JA (2010) fMR-adaptation reveals invariant coding of biological motion on the human STS. Front Hum Neurosci 4:15. CrossRef Medline

Hamilton AF, Grafton ST (2006) Goal representation in human anterior intraparietal sulcus. J Neurosci 26:1133-1137. CrossRef Medline

Hamilton, AF, Grafton ST (2008) Action outcomes are represented in human inferior frontoparietal cortex. Cereb Cortex 18:1160-1168. CrossRef Medline

Hein G, Knight RT (2008) Superior temporal sulcus-it's my area: or is it? J Cogn Neurosci 20:2125-2136. CrossRef Medline

Jackson S, Blake R (2010) Neural integration of information specifying human structure from form, motion, and depth. J Neurosci 30:838-848. CrossRef Medline

Jacquet PO, Avenanti A (2015) Perturbing the action observation network during perception and categorization of actions' goals and grips: statedependency and virtual lesion TMS effects. Cereb Cortex 25:598-608. CrossRef Medline

Johansson G (1973) Visual perception of biological motion and a model for its analysis. Percept Psychophys 14:201-211. CrossRef

Kadosh RC, Muggleton N, Silvanto J, Walsh V (2010) Double dissociation of format-dependent and number-specific neurons in human parietal cortex. Cereb Cortex 20:2166-2171. CrossRef Medline

LeDoux JE (1996) The emotional brain. New York: Simon and Shuster.

Meeren HK, de Gelder B, Ahlfors SP, Hämäläinen MS, Hadjikhani N (2013) Different cortical dynamics in face and body perception: an MEG study. PLoS One 8:e71408. CrossRef Medline

Morris JS, DeGelder B, Weiskrantz L, Dolan RJ (2001) Differential extrageniculostriate and amygdala responses to presentation of emotional faces in a cortically blind field. Brain 124:1241-1252. CrossRef Medline

Nelissen K, Borra E, Gerbella M, Rozzi S, Luppino G, Vanduffel W, Rizzolatti G, Orban GA (2011) Action observation circuits in the macaque monkey cortex. J Neurosci 31:3743-3756. CrossRef Medline

Ochiai T, Grimault S, Scavarda D, Roch G, Hori T, Rivière D, Mangin JF, Régis J (2004) Sulcal pattern and morphology of the superior temporal sulcus. Neuroimage 22:706-719. CrossRef Medline
Öhman A, Mineka S (2001) Fears, phobias, and preparedness: toward an evolved module of fear and fear learning. Psychol Rev 108:483-522. CrossRef Medline

Phillips ML, Drevets WC, Rauch SL, Lane R (2003) Neurobiology of emotion perception I: the neural basis of normal emotion perception. Biol Psychiatry 54:504-514. CrossRef Medline

Pichon S, de Gelder B, Grezes J (2008) Emotional modulation of visual and motor areas by dynamic body expressions of anger. Soc Neurosci 3:199212. CrossRef Medline

Pobric G, Hamilton AF (2006) Action understanding requires the left inferior frontal cortex. Curr Biol 16:524-529. CrossRef Medline

Puce A, Perrett D (2003) Electrophysiology and brain imaging of biological motion. Philos Trans R Soc Lond B Biol Sci 358:435-445. CrossRef Medline

R Development Core Team (2016) R: A language and environment for statistical computing. R Foundation for Statistical Computing, Vienna.

Rizzolatti G, Cattaneo L, Fabbri-Destro M, Rozzi S (2014) Cortical mechanisms underlying the organization of goal-directed actions and mirror neuron-based action understanding. Physiol Rev 94:655-706. CrossRef Medline

Romei V, Thut G, Silvanto J (2016) Information-based approaches of noninvasive transcranial brain stimulation. Trends Neurosci 39:782-795. CrossRef Medline

Rossini PM, Barker AT, Berardelli A, Caramia MD, Caruso G, Cracco RQ, Dimitrijević MR, Hallett M, Katayama Y, Lücking $\mathrm{CH}$, Maertens de Noordhout AL, Marsden CD, Murray NMF, Rothwell JC, Swash M, Tomberg C (1994) Non-invasive electrical and magnetic stimulation of the brain, spinal cord and roots: basic principles and procedures for routine clinical application: report of an IFCN committee. Electroencephalogr Clin Neurophysiol 91:79-92. CrossRef Medline

Russell JA, Fehr B (1987) Relativity in the perception of emotion in facial expressions. J Exp Psychol Gen 116:223-237. CrossRef

Sato M, Grabski K, Glenberg AM, Brisebois A, Basirat A, Ménard L, Cattaneo L (2011) Articulatory bias in speech categorization: evidence from useinduced motor plasticity. Cortex 47:1001-1003. CrossRef Medline

Saygin AP (2007) Superior temporal and premotor brain areas necessary for biological motion perception. Brain 130:2452-2461. CrossRef Medline

Schutter DJ, Hofman D, Van Honk J (2008) Fearful faces selectively increase corticospinal motor tract excitability: a transcranial magnetic stimulation study. Psychophysiology 45:345-348. CrossRef Medline

Shmuelof L, Zohary E (2006) A mirror representation of others' actions in the human anterior parietal cortex. J Neurosci 26:9736-9742. CrossRef Medline

Silvanto J, Pascual-Leone A (2008) State-dependency of transcranial magnetic stimulation. Brain Topogr 21:1-10. CrossRef Medline

Silvanto J, Muggleton NG (2008) New light through old windows: moving beyond the "virtual lesion" approach to transcranial magnetic stimulation. Neuroimage 39:549-552. CrossRef Medline

Silvanto J, Muggleton NG, Cowey A, Walsh V (2007a) Neural adaptation reveals state-dependent effects of transcranial magnetic stimulation. Eur J Neurosci 25:1874-1881. CrossRef Medline

Silvanto J, Muggleton NG, Cowey A, Walsh V (2007b) Neural activation state determines behavioral susceptibility to modified theta burst transcranial magnetic stimulation. Eur J Neurosci 26:523-528. CrossRef Medline

Silvanto J, Muggleton N, Walsh V (2008) State-dependency in brain stimulation studies of perception and cognition. Trends Cogn Sci 12:447-454. CrossRef Medline

Skuk VG, Schweinberger SR (2013) Adaptation aftereffects in vocal emotion perception elicited by expressive faces and voices. PLoS One 8:e81691. CrossRef Medline

Tamietto M, de Gelder B (2011) Sentinels in the visual system. Front Behav Neurosci 5:6. CrossRef Medline

Tamietto M, Adenzato M, Geminiani G, de Gelder B (2007) Fast recognition of social emotions takes the whole brain: interhemispheric cooperation in the absence of cerebral asymmetry. Neuropsychologia 45:836-843. CrossRef Medline

Theusner S, de Lussanet MH, Lappe M (2011) Adaptation to biological motion leads to a motion and a form aftereffect. Atten Percept Psychophys 73:1843-1855. CrossRef Medline

Troje NF, Sadr J, Geyer H, Nakayama K (2006) Adaptation aftereffects in the perception of gender from biological motion. J Vis 6(8):7 850-857. CrossRef Medline 
Tseng LY, Tseng P, Liang WK, Hung DL, Tzeng OJ, Muggleton NG, Juan CH (2014) The role of superior temporal sulcus in the control of irrelevant emotional face processing: a transcranial direct current stimulation study. Neuropsychologia 64:124-133. CrossRef Medline

Tunik E, Rice NJ, Hamilton A, Grafton ST (2007) Beyond grasping: representation of action in human anterior intraparietal sulcus. Neuroimage 36:T77-86. CrossRef Medline

Vaina LM, Lemay M, Bienfang DC, Choi AY, Nakayama K (1990) Intact "biological motion" and "structure from motion" perception in a patient with impaired motion mechanisms: a case study. Vis Neurosci 5:353-369. CrossRef Medline

van Boxtel JJ, Lu H (2013) Impaired global, and compensatory local, biological motion processing in people with high levels of autistic traits. Front Psychol 4:209. CrossRef Medline

van de Riet WA, Grezes J, de Gelder B (2009) Specific and common brain regions involved in the perception of faces and bodies and the representation of their emotional expressions. Soc Neurosci 4:101-120. CrossRef Medline

van Kemenade BM, Muggleton N, Walsh V, Saygin AP (2012) Effects of TMS over premotor and superior temporal cortices on biological motion perception. J Cogn Neurosci 24:896-904. CrossRef Medline

Webster MA, MacLeod DI (2011) Visual adaptation and face perception. Philos Trans R Soc Lond B Biol Sci 366:1702-1725. CrossRef Medline

Webster MA, Kaping D, Mizokami Y, Duhamel P (2004) Adaptation to natural facial categories. Nature 428:557-561. CrossRef Medline 